
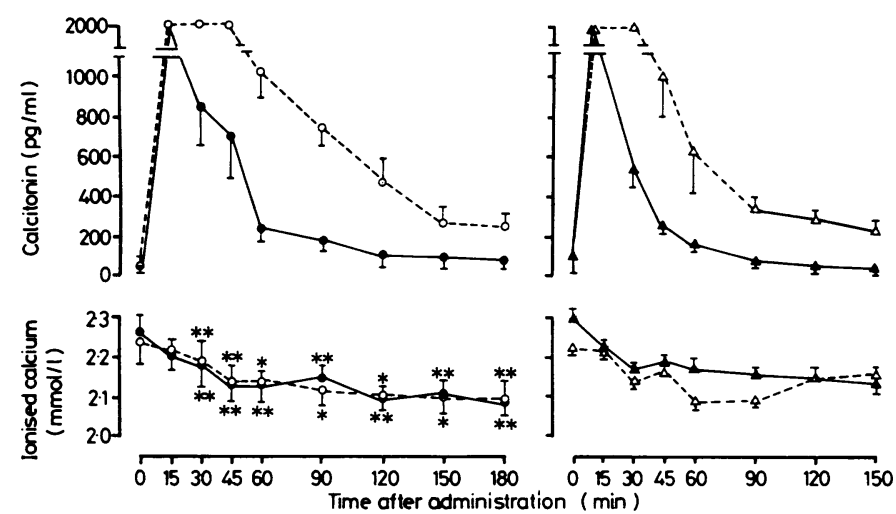

Mean (SEM) plasma concentrations of calcitonin (above) and ionised calcium (below) after (left) intravenous ( $O-.-C$ ) and intranasal (administration of calcitonin $500 \mu \mathrm{g}$ to six healthy subjects and (right) intranasal administration of human calcitonin $500 \mu \mathrm{g}(\boldsymbol{\Delta})$ and $1000 \mu \mathrm{g}(\Delta)$ to four healthy subjects.

$\mathrm{p}$ Values for time after administration $v 0 \mathrm{~min}:{ }^{*}<0.02 ;{ }^{* *}<0.01$.

Conversion: SI to traditional units-Calcium: $1 \mathrm{mmol} 1 \approx 4 \mathrm{mg} / 100 \mathrm{ml}$.

$500 \mu \mathrm{g}$, exerted the same effect on plasma calcium concentrations whether administered intravenously or intranasally, this despite the plasma calcitonin concentration being higher after intravenous than after intranasal administration. If we consider in addition that when doses of 500 and $1000 \mu \mathrm{g}$ calcitonin were used the decrease in the plasma calcium concentration was the same we must assume that in man no strict relation exists between plasma concentrations of calcitonin and calcium; alternatively, it might be suggested that the doses used in this study were always maximally effective.

Calcitonin has gained popularity in the treatment of Paget's disease of the skeleton, osteoporosis, intractable osseous pain from metastases, and hypercalcaemia, although its use in these indications is debatable and of unconfirmed value. Our study indicates that calcitonin may be given intranasally under the same or other circumstances. Further improvements in the bioavailability and metabolic efficacy of intranasally administered calcitonin may be expected with the use of aerosols, which ensure that a greater surface area of the nasal and pharyngeal mucosa is reached by the active drug.

1 Schrier RW, Leaf A. Effect of hormones on water, sodium, chloride and potassium metabolism. In: Williams RH, ed. Textbook of endocrinology. 6th ed. Philametabolism. In: Williams RH, ed. T

2 Fink G, Gennser G, Liedholm P, Thorell J. Comparison of plasma levels of LHRH in men after intravenous and intranasal administration. $f$ Endocrinol $1974 ; 63: 351-60$

3 Pontiroli AE, Alberetto M, Secchi A, Dossi G, Bosi I, Pozza G. Insulin given intranasally induces hypoglycaemia in normal and diabetic subjects. Br Med $\mathcal{f}$ 1982;284:303-6.

4 Pontiroli AE, Alberetto M, Pozza G. Intranasal glucagon raises blood glucose concentration in healthy volunteers. Br Med f 1983;287:462-3 Murlin JR, Gibb CBF, Romansky MJ, Steinhausen TB, Truax FL. Effectiveness
of perioral insulin in human diabetes. Am 7 Physiol 1940;120:709-22.

(Accepted 18 fanuary 1985)

Istituto Scientifico Ospedale San Raffaele, Cattedra di Clinica

Medica, Universitá di Milano, Milan, Italy

ANTONIO E PONTIROLI, MD, established investigator

MIRIAM ALBERETTO, MD, physician

GUIDO POZZA, MD, professor of medicine

Correspondence to: Dr A E Pontiroli.

\section{Characterisation of antibodies to insulin to help diagnose factitious hypoglycaemia}

Spontaneous hypoglycaemia is associated with several pathological disorders, including benign or malignant tumours, diseases of hepatic, renal, or endocrine systems, and inborn errors of metabolism. ${ }^{1}$ As many of these conditions can be diagnosed rapidly in a young adult presenting with hypoglycaemia only a few clinical conditions remain in the differential diagnosis.
We describe a case of hypoglycaemia in which the diagnoses of spontaneous reactive hypoglycaemia, insulinoma, autoimmune spontaneous hypoglycaemia, and factitious hypoglycaemia were all considered. Factitious hypoglycaemia was confirmed by specific characterisation of the antibodies to insulin that were present.

\section{Case report}

A 16 year old girl admitted to hospital as an emergency was conscious, hypothermic ( $32 \mathrm{C}$ ), and hypoglycaemic (glucose concentration $1.2 \mathrm{mmol} / 1$ $(21.6 \mathrm{mg} / 100 \mathrm{ml}))$. At the age of 14 she had been investigated for a similar episode with an extended oral glucose tolerance test and had been diagnosed as having spontaneous reactive hypoglycaemia. Her father and sister were known to have insulin dependent diabetes (treated with soluble and isophane insulin), but neither was living at home. Although she had been asymptomatic since then, an insulinoma needed to be excluded. A prolonged $50 \mathrm{~g}$ oral glucose tolerance test was repeated, which again produced reactive hypoglycaemia (figure). As up to one fifth of normal subjects can develop reactive hypoglycaemia after a glucose load this finding was not considered to be diagnostically important. ${ }^{1}$ Concentrations of insulin were reported as too high to record. A 24 hour fast followed by exercise did not produce hypoglycaemia, and an insulin stress test $(0.15 \mathrm{U} / \mathrm{kg})$ did not result in adequate hypoglycaemia and could not therefore be interpreted. As the findings of unrecordable high insulin concentrations and resistance to exogenous insulin were attributed to the presence of antibodies to insulin an insulinoma was considered to be unlikely.

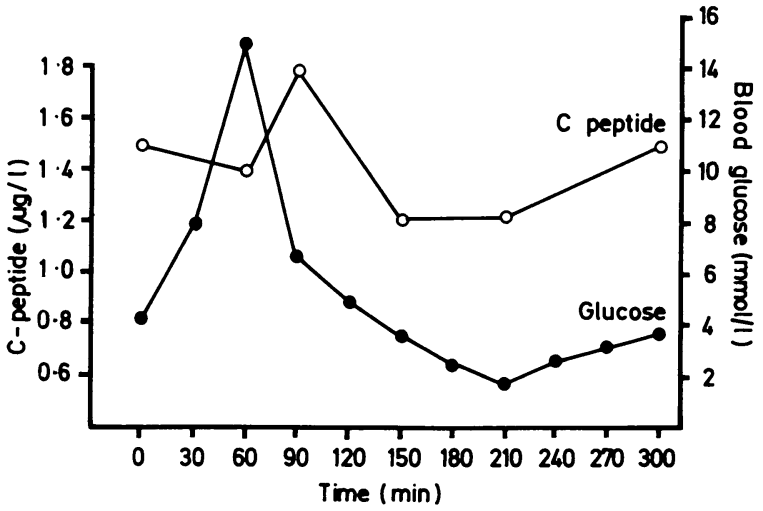

Results of prolonged (five hour) oral glucose tolerance test $(50 \mathrm{~g}$ ), with $C$ peptide and glucose measurements showing reactive hypoglycaemia at 210 minutes.

Conversion: SI to traditional units-Blood glucose: $1 \mathrm{mmol} \mathrm{I}=$ $18 \mathrm{mg} 100 \mathrm{ml}$

Antibodies to insulin were investigated further by immunochemical characterisation to distinguish between spontaneous autoimmune hypoglycaemia and factitious hypoglycaemia. This investigation indicated considerable formation of antibodies to bovine insulin $\left(68.2^{\circ}{ }^{\circ} \text { binding }\right)^{2}$ and to the $C$ peptide moiety of bovine proinsulin $\left(64 \cdot 8^{\circ} \text {. binding }\right)^{3}$ Lateral bruising was noted on both thighs, which later developed into mild lipoatrophy. Factitious hypoglycaemia was diagnosed. She did not admit to abuse of insulin and refused to return to any follow up clinics.

\section{Comment}

Although factitious hypoglycaemia is an uncommon cause of hypoglycaemia, biochemical or immunological tests that confirm the diagnosis are of great interest to the clinician. In a patient without antibodies to insulin the simultaneous presence of a low concentration of glucose, high concentration of immunoreactive insulin, and suppressed $\mathrm{C}$ peptide is considered to be pathognomonic of the secret use of insulin. ${ }^{1}$ Alternatively, a species specific antibody can be used to discriminate between human and bovine insulin in the plasma. ${ }^{1}$ In a patient with antibodies to insulin, however, these tests are unreliable as accurate measurements of plasma insulin concentrations are impossible and $\mathrm{C}$ peptide concentrations may not be suppressed due to the antibody binding proinsulin containing the $\mathrm{C}$ peptide moiety. ${ }^{5}$ Neither do they distinguish between autoimmune spontaneous hypoglycaemia and factitious hypoglycaemia. ${ }^{1}$

The specific binding characteristics of circulating antibodies to insulin, however, can be used to confirm cases of factitious hypoglycaemia. Bovine insulin differs from human insulin by only three amino acids, and the antibodies formed due to the repeated injection 
of bovine insulin often cross react with human insulin. ${ }^{2}$ The antibodies formed against the $\mathrm{C}$ peptide portion of the bovine proinsulin molecule (present as a contaminant in some preparations of insulin) can, however, be distinguished immunologically and if present provide good evidence of previous administration of bovine insulin. ${ }^{3} \mathrm{~A}$ further advantage of diagnosing factitious hypoglycaemia in this way is that the sample can be taken at any stage and is not dependent on the patient being hypoglycaemic. Proof of exogenous administration, however, becomes more difficult when highly purified pork or human insulin has been administered.

We thank Professor V Marks and Dr D J Teale, St Luke's Hospital, Guildford, and Drs C Gordon and I Laing, Manchester Royal Infirmary, for their help and advice.

1 Marks V, Rose FC. Hypoglycaemia. 2nd ed. Oxford: Blackwell Scientific Publications, 1981

Reeves WG, Kelly $U$. Insulin antibodies induced by bovine insulin therapy. Clin Exp Immunol 1982;50:163-70.

3 Reeves WG, Douglas CA. C-peptide antibodies induced by bovine insulin therapy. Clin Exp Immunol 1982;50:171-7.

Bauman WA, Yalow RS. Differential diagnosis between endogenous and exogenous insulin induced refracto

5 Meistas MT, Kumar MS, Schumacher OP. Diagnosis of self induced hypoinsulinaemia in an insulin dependent diabetic patient by radioimmunoassay of free C-peptide. Clin Chem 1981;27:184-6.

(Accepted 18 fanuary 1985)

Department of Clinical Biochemistry and Medicine, Hope Hospital, Salford M6 8HD

I ROBERTS, MSC, MB, senior registrar

H COHEN, MB, FRCP, consultant physician

Department of Immunology, University Hospital, Queen's Medical Centre, Nottingham NG7 2UH

W G REEVES, MRCS, LRCP, consultant immunologist

Correspondence to: Dr Ian Roberts.

\section{Neurological complications of pulmonary arteriovenous malformations}

Pulmonary arteriovenous fistulas are uncommon congenital lesions, which sometimes form part of the syndrome of hereditary haemorrhagic telangiectasia. I report two cases that illustrate some of the clinical features of the lesions and, more importantly, highlight the rarely recognised association with neurological problems. ${ }^{1}$

\section{Case 1}

A previously healthy woman aged 47 presented to her optician suffering from blurred vision and headaches. A defect in the upper temporal field was found in the left eye. The inferior nasal branch of the retinal artery was occluded, but no embolus was seen. Auscultation over the chest elicited a continuous murmur loudest in the right axilla. There was no cyanosis or finger clubbing.

The haemoglobin concentration on presentation was $12.0 \mathrm{~g} / \mathrm{dl}$ (packed cell volume 0.36 ). Routine biochemistry, including plasma lipid and blood glucose concentrations, gave normal results. A radiograph of the chest showed a rounded opacity in the right lower lobe. Tomography and pulmonary angiography confirmed this as a pulmonary arteriovenous fistula. Carotid angiography gave normal results. She underwent resection of the right lower lobe and afterwards suffered no further neurological problems, although the field defect persisted.

\section{Case 2}

A 34 year old man who smoked presented with aphasia and right sided sensory symptoms of sudden onset. These completely resolved within 24 hours. Subsequent examination yielded normal results except for central cyanosis and finger clubbing. No bruit was audible over the chest. Seven years earlier a routine radiograph of the chest had shown a pulmonary arteriovenous fistula, which was confirmed by tomography. No action had been taken. A recent radiograph (figure) had shown two rounded opacities in the right lower lobe, rather larger than before. Pulmonary arteriography showed three fistulas in the right lower and middle lobes.
He was hypoxaemic (oxygen pressure $8.6 \mathrm{kPa}(65 \mathrm{~mm} \mathrm{Hg})$ ) and hypocapnoeic (carbon dioxide pressure $3.4 \mathrm{kPa}(26 \mathrm{~mm} \mathrm{Hg}$ )). This was compatible with a right to left shunt. The haemoglobin concentration was $18.6 \mathrm{~g} / \mathrm{dl}$ (packed cell volume 0.57 ). Routine biochemistry, including plasma lipid and blood glucose concentrations, and echocardiography, computed tomography of the brain, and bilateral carotid angiography produced normal results. He underwent resection of the right middle and lower lobes. Eight months later the blood gas tensions were normal (oxygen pressure $11.6 \mathrm{kPa}$ $(87 \mathrm{~mm} \mathrm{Hg}$ ), carbon dioxide pressure $5.0 \mathrm{kPa}(38 \mathrm{~mm} \mathrm{Hg})$, and the haemoglobin concentration had fallen to $14.9 \mathrm{~g} / \mathrm{dl}$ (packed cell volume 0.47 )). He sustained no further transient ischaemic attacks.

\section{Comment}

Pulmonary arteriovenous fistulas may be associated with exertional dyspnoea, haemoptysis, and chest pain. ${ }^{2}$ Neither patient suffered these symptoms, but cumulatively they illustrate the common physical signs: cyanosis, finger clubbing, and continuous murmur Many patients have neither symptoms (about 38\%) nor signs. ${ }^{2}$

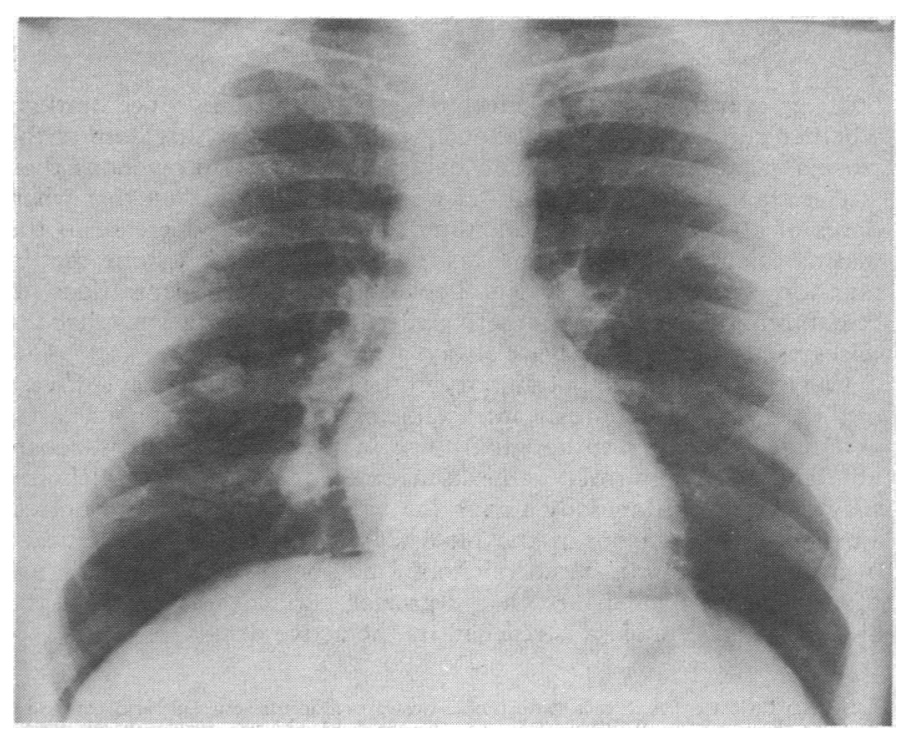

Posteroanterior chest radiograph showing pulmonary arteriovenous malformation (case 2)

Several explanations for these neurological deficits are possible. In case 2 polycythaemia causing increased blood viscosity $(1.31 \mathrm{mPa}$ $(\mathrm{cP})$, normal $1 \cdot 15-1 \cdot 25 \mathrm{mPa} \mathrm{s}$ ) could have resulted in cerebral thrombosis, although the short duration of the deficit might favour an embolic mechanism. ${ }^{34}$ Haemorrhage from associated cerebral arteriovenous malformations has been suggested, but in both cases carotid angiography yielded normal results. Emboli could have arisen from the pulmonary arteriovenous fistulas secondary to turbulent flow, or perhaps from deep veins with "paradoxical embolisation" through the right to left shunt. It is this shunt that accounts for the cyanosis and polycythaemia. Interestingly, in case 2 the polycythaemia was predominantly due to a reduction in plasma volume $(33.7 \mathrm{ml} / \mathrm{kg}$, normal $40-50 \mathrm{ml} / \mathrm{kg}$ ) with little increase in red cell mass $(31.9 \mathrm{ml} / \mathrm{kg}$, normal $25-35 \mathrm{ml} / \mathrm{kg}$ ). This "stress" type polycythaemia is clearly not the usual response to hypoxaemia, although it reversed postoperatively (plasma volume $40.7 \mathrm{ml} / \mathrm{kg}$, red cell mass $26.9 \mathrm{ml} / \mathrm{kg}$ ).

Gomes et al reviewed 47 patients with pulmonary arteriovenous fistulas. ${ }^{2}$ Of 19 treated conservatively, three, aged 45-55, suffered fatal cerebrovascular accidents. They recommended that patients with symptoms, enlarging fistulas, and associated hereditary haemorrhagic telangiectasia should be offered surgery owing to the higher incidence of complications.

We believe that the clinical importance of pulmonary arteriovenous fistulas is widely underestimated. If detected they should be fully investigated and considered for surgical treatment.

I thank Dr P S Monro, Dr F G Campbell, and Mr N L Wright for their permission to report these cases; Dr A G Wilson for interpreting the radiographs; and Helen Gadsby for preparing the manuscript. 